\title{
Knowledge and provision of misoprostol among pharmacy workers in Senegal: a cross sectional study
}

\author{
Kate Reiss ${ }^{1}$, Katharine Footman ${ }^{* *}$, Eva Burke ${ }^{2}$, Nafissatou Diop ${ }^{3}$, Ramatoulaye Ndao $^{2}$, Babacar Mane ${ }^{3}$,
} Maaike van $\mathrm{Min}^{1}$ and Thoai D. Ngo'

\begin{abstract}
Background: Making misoprostol widely available for management of postpartum haemorrhage (PPH) and post abortion care (PAC) is essential for reducing maternal mortality. Private pharmacies (thereafter called "pharmacies") are integral in supplying medications to the general public in Senegal. In the case of misoprostol, pharmacies are also the main supplier to public providers and therefore have a key role in increasing its availability. This study seeks to understand knowledge and provision of misoprostol among pharmacy workers in Dakar, Senegal.

Methods: A cross-sectional survey was conducted in Dakar, Senegal. 110 pharmacy workers were interviewed face-toface to collect information on their knowledge and practice relating to the provision of misoprostol.

Results: There are low levels of knowledge about misoprostol uses, registration status, treatment regimens and side effects among pharmacy workers, and corresponding low levels of training on its uses for reproductive health. Provision of misoprostol was low; of the $72 \%(n=79)$ of pharmacy workers who had heard of the product, $35 \%(n=27)$ reported selling it, though rarely for reproductive health indications. Almost half $(49 \%, n=25)$ of the respondents who did not sell misoprostol expressed willingness to do so. The main reasons pharmacy workers gave for not selling the product included stock outs (due to product unavailability from the supplier), perceived lack of demand and unwillingness to stock an abortifacient.

Conclusions: Knowledge and availability of misoprostol in pharmacies in Senegal is low, posing potential challenges for delivery of post-abortion care and obstetric care. Training is required to address low levels of knowledge of misoprostol registration and uses among pharmacy workers. Barriers that prevent pharmacy workers from stocking misoprostol, including weaknesses in the supply chain and stigmatisation of the product must be addressed. Low reported sales for reproductive health indications also suggest limited prescribing of the product by health providers. Further research is needed to explore the reasons for this barrier to misoprostol availability.
\end{abstract}

Keywords: Misoprostol, Post abortion care, Postpartum haemorrhage, Pharmacy, Maternal mortality, Senegal, Reproductive health

\footnotetext{
* Correspondence: katy.footman@mariestopes.org

${ }^{1}$ Health Systems Department, Marie Stopes International, 1 Conway Street,

London W1T 6LP, UK

Full list of author information is available at the end of the article
} 


\section{Background}

Senegal has made progress toward reducing maternal mortality over the past two decades. However, with a maternal mortality ratio (MMR) estimated at 315 per 100,000 live births in 2015 [1], Senegal was not able to meet its Millennium Development Goal target of 190 by 2015 [2], and further advances are needed. While little data exists on the causes of maternal deaths in Senegal, post-partum haemorrhage is responsible for an estimated 34\% of maternal deaths in sub-Saharan Africa [3]. Globally, a large proportion of deaths in early pregnancy are also due to unsafe abortion $[4,5]$. It has been demonstrated that making misoprostol readily available in low-resource settings for management of postpartum haemorrhage $(\mathrm{PPH})$ and post abortion care (PAC) can have a significant impact on reducing maternal deaths $[6,7]$. Misoprostol is particularly appropriate for low resource settings as it does not require refrigeration and can be administered at the community-level by auxiliary midwives $[8,9]$.

Misoprostol was included in the World Health Organization's Essential Medicines List (EML) in 2005 and was named for management of incomplete abortion and miscarriage in 2009 and for the prevention of $\mathrm{PPH}$ and induction of labour in 2011 [10-12]. In 2013, misoprostol was registered on the EML in Senegal as an anti-haemorrhagic and hemostatic product, and is available on the market for the treatment of duodenal and gastric ulcers, prevention of nonsteroidal anti-inflammatory drugs (NSAID)-induced peptic ulcers, the prevention and treatment of $\mathrm{PPH}$, PAC, intra-uterine foetal death (IUFD), and ripening of the cervix. The EML has yet to be widely disseminated in Senegal. Several brands of misoprostol exist on the market today, one of which, Misoclear ${ }^{\oplus}$, is registered for gynaecological indications such as PPH and PAC. Recent research on misoprostol provision at the community level for PPH and PAC in Senegal has shown high levels of efficacy and acceptability $[13,14]$ and found it to be more cost effective for $\mathrm{PPH}$ prevention than oxytocin [15]. However, misoprostol remains underused $[13,14]$, and its availability in public and private health facilities is limited [16].

Misoprostol is also an abortifacient. Abortion is legal in Senegal only to save the mother's life [17]. Evidence suggests that women recourse to unsafe procedures outside the health system when attempting to terminate pregnancies for other reasons [18], contributing to Senegal's high rates of maternal morbidity and mortality $[1,19]$. In some restrictive settings around the world, it has been documented that women are using misoprostol purchased over the counter as a safer alternative to high risk methods of pregnancy termination such as those undertaken by untrained providers in unhygienic settings
[20, 21]. Awareness of misoprostol's use for termination of pregnancy among providers and pharmacy workers is not documented in Senegal.

Global evidence indicates that private pharmacies (thereafter called "pharmacies") and pharmacy workers are often the first and sometimes only point of contact with the health system and therefore play an important role in providing basic health information and services, including misoprostol, in many countries [22-27]. Pharmacies may be chosen because of their long opening hours, short waiting times, convenient locations, anonymity, and because they offer greater availability of medicines than public health facilities [26]. Despite this potential, there are concerns about the quality of care provided by pharmacies; pharmacy curricular may not include courses on the role of pharmacists as community health advisors and frontline staff may not be formally trained on medications, regimen and doses [26]. In Senegal, a University awarded diploma in pharmacy is a required to open and run a pharmacy, but not to sell medications from the outlet. Availability of misoprostol from pharmacies is also a concern, as pharmacists may be unwilling to stock and dispense a medication that can be used as an abortifacient [27].

Pharmacies are integral to the supply of medications in Senegal; selling misoprostol both to the general public and to providers. In 2014, the government opened a tender to purchase misoprostol for the public sector; however, at the time of writing, public providers were mostly accessing the product through pharmacies. To enable continued reductions in MMR in Senegal, it is important to ensure that misoprostol is widely available in pharmacies. This study seeks to understand knowledge and provision of misoprostol among pharmacies in Dakar, Senegal. Specifically, its objectives are (i) to document knowledge of misoprostol among pharmacy workers; (ii) to document the availability of and demand for misoprostol in the pharmacies; and (iii) to document selfreported provision practices by pharmacy workers.

\section{Methods}

In September 2013, Marie Stopes International and the Population Council conducted a cross-sectional survey with pharmacy workers in Dakar, Senegal [18]. We obtained the list of all 557 registered pharmacies in the Dakar region (Dakar city and three suburbs located between 15 and $30 \mathrm{~km}$ from Dakar city centre) from the Order of Pharmacists, and used simple random sampling to select 110 pharmacies for inclusion in the study. Endorsement for the study was given by the Order of Pharmacists who contacted pharmacy workers in writing prior to data collection to endorse the study. Within each pharmacy, one worker was selected for a face-toface interview. Selection criteria were (i) being involved 
in selling/distributing medicine; and (ii) being over 18 years of age. In each pharmacy, the owner or manager was approached first, and if they did not meet the eligibility criteria, for example if they did not directly sell or distribute medicine, the next most senior and eligible staff member was invited to participate. Pharmacy workers received an information sheet explaining the study, and were asked to give informed consent prior to interview. Interviewers were trained to explain the importance of the study and to ensure participants understood that their responses would be anonymised. Interviews took place in a setting within the pharmacy where the interview could not be overheard and where the interviewee felt comfortable providing information. A standardised, structured questionnaire was administered by a trained interviewer. The questionnaire collected information on pharmacy characteristics, staff background, knowledge and current practice relating to misoprostol as well as current frequency of misoprostol sales. Participants were able to refer to sales registers where needed. The questionnaire also included openended "Other" categories for some questions to collect answers not pre-coded, and respondents were given the opportunity to provide additional comments at the end of the interview. The instrument was pre-tested in eight pharmacies in Dakar.

Data were entered into an access database using Epi Info. Double data entry was used to check for data entry errors. Quantitative data were analysed descriptively using Stata 13 (StataCorp LP, College Station, TX, USA).

\section{Results}

One hundred and ten structured interviews were completed, a response rate of $100 \%$. Table 1 shows that about half $(49 \%, n=54)$ of respondents worked in pharmacies in Dakar city, and half $(51 \%, n=56)$ in pharmacies in the suburbs. The mean age of respondents was 41 , and $63 \%(n=69)$ of them were male. While overall, $82 \%(n=89)$ had a relevant degree from a (public) university or private institution, data show heterogeneity in training by location: all respondents in Dakar city had some level of professional or university training whereas $36 \%(n=20)$ of pharmacy workers in the suburbs had only received on-the-job training.

\section{Knowledge and training of pharmacy workers}

Table 2 shows that a high proportion of respondents had heard of misoprostol $(72 \%, n=79)$. Gastric and duodenal ulcer was the condition for which knowledge of registration and use of the product were highest. There was little awareness that misoprostol was registered for PPH prevention $(1 \%, n=1)$ and treatment $(3 \%, n=2)$, PAC $(13 \%, n=10)$, and other conditions. Knowledge of misoprostol's reproductive health uses was highest for

Table 1 Characteristics of respondents

\begin{tabular}{|c|c|c|c|c|c|c|}
\hline & \multicolumn{2}{|c|}{ Dakar city } & \multicolumn{2}{|c|}{ Suburbs $^{a}$} & \multicolumn{2}{|c|}{ Total } \\
\hline & $\mathrm{N}$ & $\%$ & $\mathrm{~N}$ & $\%$ & $\mathrm{~N}$ & $\%$ \\
\hline Total & 54 & 49 & 56 & 51 & 110 & 100 \\
\hline \multicolumn{7}{|l|}{ Gender } \\
\hline Male & 31 & 57 & 38 & 68 & 69 & 63 \\
\hline Female & 23 & 43 & 18 & 32 & 41 & 37 \\
\hline \multicolumn{7}{|l|}{$A g e^{b}$} \\
\hline $22-30$ & 11 & 21 & 7 & 13 & 18 & 17 \\
\hline $31-40$ & 12 & 23 & 28 & 53 & 40 & 38 \\
\hline $41-50$ & 18 & 34 & 14 & 26 & 32 & 30 \\
\hline $51-65$ & 12 & 23 & 4 & 8 & 16 & 15 \\
\hline
\end{tabular}

Education

Primary

Secondary

University degree

Size of pharmacy staff

$2-3$

4-6

$7+$

Position held

\begin{tabular}{lllllll} 
Owner & 24 & 44 & 22 & 39 & 46 & 42 \\
Manager & 5 & 9 & 10 & 18 & 15 & 14 \\
Employee & 25 & 46 & 23 & 41 & 48 & 44 \\
$\quad$ Trainee & 0 & 0 & 1 & 2 & 1 & 1 \\
Training level $^{d}$ & & & & & & \\
On the job training & 0 & 0 & 20 & 36 & 20 & 18 \\
Private institution & 20 & 37 & 8 & 15 & 28 & 26 \\
(Public) University degree & 34 & 63 & 27 & 49 & 61 & 56 \\
\hline
\end{tabular}

${ }^{a}$ Suburbs regroup pharmacies in the districts of Pikine, Guédiawaye and Rufisqu ${ }^{b}$ Data missing for one pharmacy worker in Dakar and three pharmacy workers in the Suburbs 'Data missing for one pharmacy worker in Dakar, one pharmacy worker in the Suburbs didn't know the number of staff ${ }^{\mathrm{d} D a t a}$ missing for one pharmacy worker in the Suburbs

termination of pregnancy $(38 \%, n=30)$ and PAC $(13 \%$, $n=10)$, and lowest for conditions such as prevention $(1 \%, n=1)$ and treatment $(4 \%, n=3)$ of $\mathrm{PPH}$, treatment of IUFD $(1 \%, n=1)$ and cervical ripening $(3 \%, n=2)$. Knowledge that misoprostol could be used for a condition did not translate into knowledge of the regimen. For example, $31 \%(n=18)$ of the respondents who knew misoprostol could be used to treat gastric and duodenal ulcer reported that they did not know the regimen. Furthermore, $60 \%(n=6)$ of those who knew misoprostol could be used for PAC reported not knowing its regimen and only $20 \%(n=2)$ gave the correct total dose and route of administration $(600 \mathrm{mcg}$ administered orally or $400 \mathrm{mcg}$ administered sublingually). Additionally, almost half of respondents that had heard of misoprostol could not name a side effect (Table 2). 
Table 2 Pharmacy worker knowledge of misoprostol

\begin{tabular}{|c|c|c|c|c|}
\hline & \multicolumn{2}{|c|}{ Number } & \multicolumn{2}{|c|}{ Percent } \\
\hline Respondent had heard of misoprostol & \multicolumn{2}{|l|}{79} & \multicolumn{2}{|l|}{72} \\
\hline \multirow[t]{2}{*}{ Knowledge of conditions } & \multicolumn{2}{|c|}{ Used for } & \multicolumn{2}{|c|}{ Registered for } \\
\hline & N & $\%$ & N & $\%$ \\
\hline Duodenal or gastric ulcer & 59 & 75 & 48 & 61 \\
\hline Prophylaxis of NSAID-induced peptic ulcers & 5 & 6 & 4 & 5 \\
\hline Prevention of PPH & 1 & 1 & 1 & 1 \\
\hline Treatment of PPH & 3 & 4 & 2 & 3 \\
\hline PAC & 10 & 13 & 10 & 13 \\
\hline Treatment for intrauterine fetal death (IUFD) & 1 & 1 & 0 & 0 \\
\hline Cervical ripening & 2 & 3 & 1 & 1 \\
\hline Termination of pregnancy & 30 & 38 & 5 & 6 \\
\hline Knowledge of storage instructions & \multicolumn{2}{|l|}{$N$} & \multicolumn{2}{|l|}{$\%$} \\
\hline Store away from heat & \multicolumn{2}{|l|}{66} & \multicolumn{2}{|l|}{84} \\
\hline Store away from moisture & \multicolumn{2}{|l|}{22} & \multicolumn{2}{|l|}{28} \\
\hline \multicolumn{5}{|l|}{ Knowledge of side effects } \\
\hline Could not name any side effects & \multicolumn{2}{|l|}{37} & \multicolumn{2}{|l|}{47} \\
\hline Diarrhoea & \multicolumn{2}{|l|}{6} & \multicolumn{2}{|l|}{8} \\
\hline Nausea & \multicolumn{2}{|l|}{4} & \multicolumn{2}{|l|}{5} \\
\hline Fever/chills & \multicolumn{2}{|l|}{3} & \multicolumn{2}{|l|}{4} \\
\hline Weakness & \multicolumn{2}{|l|}{5} & \multicolumn{2}{|l|}{6} \\
\hline Bleeding & \multicolumn{2}{|l|}{6} & \multicolumn{2}{|l|}{8} \\
\hline Headaches & \multicolumn{2}{|l|}{3} & \multicolumn{2}{|l|}{4} \\
\hline Dizziness & \multicolumn{2}{|l|}{11} & \multicolumn{2}{|l|}{14} \\
\hline Abortion & \multicolumn{2}{|l|}{10} & \multicolumn{2}{|l|}{13} \\
\hline
\end{tabular}

For misoprostol to be used effectively, it should be stored away from heat and moisture, but the majority of respondents were only aware of the need to keep misoprostol protected from heat (misoprostol in Senegal is packaged in moisture resistant blister packaging, however it is still recommended practice to minimise exposure to humidity).

While the majority of respondents that had heard of misoprostol reported ever receiving information or training on misoprostol, the predominant source of information was literature or brochures $(45 \%, n=22)$ (Table 3). Other sources of information on misoprostol included colleagues $(20 \%, n=10)$ and medical representatives or pharmaceutical companies $(22 \%, n=11)$. Just $10 \%(n=5)$ of respondents indicated receiving information or training on misoprostol from a University. A low proportion of pharmacy workers had received training on post abortion care $(12 \%, n=6)$, while no respondents had received information about misoprostol use to prevent or treat $\mathrm{PPH}$, cervical ripening or IUFD. Over twothirds $(67 \%, n=33)$ had received information regarding the treatment of duodenal or gastric ulcer. $86 \%(n=67)$
Table 3 Training and training needs on misoprostol among pharmacy workers who had heard of the drug

\begin{tabular}{|c|c|c|}
\hline & Number & Percent \\
\hline Respondent had received information/training ${ }^{a}$ & 49 & 62 \\
\hline \multicolumn{3}{|l|}{ Source of information/training } \\
\hline Colleague & 10 & 20 \\
\hline Doctor & 4 & 8 \\
\hline Medical representative/pharmaceutical company & 11 & 22 \\
\hline Literature/Brochures & 22 & 45 \\
\hline University & 5 & 10 \\
\hline Client & 2 & 4 \\
\hline Television or Internet & 2 & 4 \\
\hline \multicolumn{3}{|l|}{ Conditions trained in } \\
\hline Duodenal or gastric ulcer & 33 & 67 \\
\hline Prophylaxis of NSAID-induced peptic ulcers & 3 & 6 \\
\hline Prevention or treatment of $\mathrm{PPH}$ & 0 & 0 \\
\hline PAC & 6 & 12 \\
\hline Treatment IUFD & 0 & 0 \\
\hline Cervical ripening & 0 & 0 \\
\hline $\begin{array}{l}\text { Respondent reported they do not feel confident } \\
\text { providing misoprostol to end users }{ }^{\text {a, }} \mathrm{b}\end{array}$ & 40 & 51 \\
\hline $\begin{array}{l}\text { Respondent wanted more information } \\
\text { or support }{ }^{a, b}\end{array}$ & 67 & 86 \\
\hline \multicolumn{3}{|l|}{ Training topics needed } \\
\hline Uses of misoprostol & 25 & 37 \\
\hline Storage of misoprostol & 2 & 3 \\
\hline Dosage & 19 & 28 \\
\hline Method of administration & 5 & 7 \\
\hline Side effects & 20 & 30 \\
\hline Complications & 14 & 21 \\
\hline All aspects & 39 & 58 \\
\hline
\end{tabular}

${ }^{\mathrm{a} A m o n g}$ those respondents who had heard of misoprostol ${ }^{\mathrm{b}}$ Data missing from one pharmacy worker

of respondents wanted more support or information about misoprostol, and 51\% $(n=40)$ reported they do not feel confident providing misoprostol to end users. Among respondents desiring more information, the most commonly requested topics were the uses of misoprostol $(37 \%, n=25)$, its side effects $(30 \%, n=20)$ and dosage $(28 \%, n=19)$. However, $58 \%(n=39)$ of respondents wanted training on all aspects of misoprostol.

\section{Provision of misoprostol and reasons for not selling it}

Table 4 shows that of the 79 respondents who had heard of misoprostol, 27 (35\%) reported selling it. They sold misoprostol most commonly to men $(56 \%, n=15)$, married women $(56 \%, n=15)$ and unmarried women (41\%, $n=11)$. No respondents reported selling misoprostol to 
Table 4 Self-reported provision of misoprostol among 27 pharmacy workers

\begin{tabular}{|c|c|c|}
\hline & Number & Percent \\
\hline Pharmacies sell misoprostol $^{a}$ & 27 & 35 \\
\hline Brands sold & \multicolumn{2}{|c|}{$\begin{array}{l}\text { Price per box }[95 \% \mathrm{Cl}] \text { (West } \\
\text { African CFA Franc) }\end{array}$} \\
\hline \multirow[t]{2}{*}{ Cytotec (60 x 200mcg doses/box) } & \multicolumn{2}{|l|}{16,376} \\
\hline & \multicolumn{2}{|c|}{$[13,824 ; 18,927]$} \\
\hline \multirow[t]{2}{*}{ Misoclear (10 x 200mcg doses/box) } & \multicolumn{2}{|l|}{2162} \\
\hline & \multicolumn{2}{|c|}{$[2149 ; 2176]$} \\
\hline \multirow[t]{2}{*}{ Arthotec $(30 \times 200 \mathrm{mcg}$ doses/box $)$} & \multicolumn{2}{|l|}{5701} \\
\hline & \multicolumn{2}{|c|}{$[5369 ; 6032]$} \\
\hline Clients misoprostol sold to & $\mathrm{N}$ & $\%$ \\
\hline Health care providers & 8 & 30 \\
\hline Married women & 15 & 56 \\
\hline Unmarried women & 11 & 41 \\
\hline Adolescents & 0 & 0 \\
\hline Men & 15 & 56 \\
\hline Conditions misoprostol sold for & N & $\%$ \\
\hline Duodenal or gastric ulcer & 17 & 63 \\
\hline Prophylaxis of NSAID-induced peptic ulcers & 2 & 7 \\
\hline Prevention or treatment of $\mathrm{PPH}$ & 0 & 0 \\
\hline Post abortion care & 1 & 4 \\
\hline Treatment for intrauterine fetal death (IUFD) & 0 & 0 \\
\hline Termination of pregnancy & 1 & 4 \\
\hline
\end{tabular}

${ }^{a}$ Among 79 respondents who had heard of misoprostol, data missing for one pharmacy worker

adolescents. $30 \%(n=8)$ of respondents reported selling misoprostol to health providers, most commonly to doctors $(19 \%, n=5)$ and midwives $(7 \%, n=3)$ (not shown). Sales were overwhelmingly reported to be for duodenal or gastric ulcer $(63 \%, n=17)$. Sale for reproductive health care uses was rarely mentioned.

Just under half $(49 \%, n=25)$ of the 51 respondents who had heard of but didn't sell misoprostol expressed interest in and willingness to stock the product. The most common reasons for not stocking misoprostol were lack of demand $(56 \%, n=30)$, unavailability of the product $(46 \%, n=24)$ and unwillingness to stock abortifacients $(42 \%, n=23)$.

\section{Demand for misoprostol}

Whether they sold misoprostol or not, pharmacy workers reported having received requests for information about and/or purchase of the product. For example, $15 \%(n=12)$ of study respondents who had heard of misoprostol reported receiving requests from health professionals for information about the product. The majority of the $12(75 \%, n=9)$ reported receiving requests from midwives. Providers most commonly wanted to know misoprostol's indications $(58 \%, n=7)$ and its side effects $(42 \%, n=5)$.

Among the 27 pharmacy workers who reported selling misoprostol, $22 \%(n=6)$ reported receiving requests to purchase misoprostol over the counter, i.e. without a prescription. No pharmacy worker reported selling it without prescription. Over the counter requests had been received for treatment of gastric ulcer (three respondents) and to terminate pregnancy (one respondent). Three respondents reported receiving clients who did not specify the indication.

Among the 52 respondents who said that they did not sell misoprostol, 21\% $(n=11)$ reported experiencing a demand for the product from health professionals, and $71 \%(n=37)$ reported demand from end users. A small number $(8 \%, n=3)$ said that the demand was for termination of pregnancy. However, the majority $(62 \%$, $n=23$ ) reported not asking the indication for which clients wanted misoprostol.

\section{Discussion}

This study found low levels of knowledge about misoprostol use, registration status, treatment regimens and side effects among pharmacy workers in Dakar, Senegal. Similar findings have recently been reported in Tanzania and Nigeria [28-30]. Although the majority of pharmacy workers had received some form of information or training on misoprostol, it was often only in the form of literature or brochures, and only on the treatment of duodenal or gastric ulcer. Pharmacy workers expressed high levels of desire for information or support on misoprostol.

As expected, given low levels of knowledge, the proportion of pharmacy workers stocking and providing misoprostol was also low, and very few respondents reported selling the product for reproductive health uses. However, half of the respondents who reported that they were not currently selling misoprostol said they were willing to stock it; their reasons for not selling the medicine were concerns about stock outs and perceived lack of demand. Recently, steps taken in Senegal to strengthen the supply chain have been successful in preventing stock outs of contraceptives [22]. Such efforts should also be applied to misoprostol.

Globally there is a critical shortage of highly-skilled healthcare workers such as physicians, nurses and midwives [31]. Expanding the role of pharmacists is recommended as one strategy for facilitating increased access to medications and reducing pressure on other areas of the health system [32,33]. Pharmacists also have a vital role in assuring the effectiveness of medications and can prevent harm from incorrect use [32, 33]. As the scope and complexity of the pharmacist's role increases, their competencies and skills need to be kept up-to-date 
though continued professional development activities [33]. In Senegal both public and private healthcare providers (midwives, nurses and physicians) procure medications from pharmacies. As well as being asked to sell misoprostol, $15 \%$ of pharmacy workers who had heard of the medication reported receiving requests from health professionals for information about it, further highlighting the importance of the pharmacist's role and suggesting a lack of knowledge about misoprostol among other health professionals.

Oxytocin is the standard treatment for $\mathrm{PPH}$, however lack of skilled health providers, lack of transportation and the medications' need for refrigeration mean that it is often not accessible to women in Senegal, particularly in rural areas [13]. A recent trial in a rural area of Senegal found misoprostol administered by auxiliary midwives for PPH prevention both as effective as oxytocin and feasible to use [13, 15]. Similarly, misoprostol presents an opportunity for increased access to PAC in Senegal: a 2012 survey found that many poor and rural women don't receive treatment for complications of abortion [18]. The survey found that some health posts (lowest level of nurse or midwife staffed public health facility) in rural areas of the country were not equipped to provide PAC but also noted that fear of criminal charges and stigma may inhibit access to existing services [18]. Unlike surgical PAC (manual or electric vacuum aspiration or dilation and curettage), misoprostol requires no surgical skills or equipment to administer making it feasible to scale up in resource scarce settings [34]. However, there is limited availability of misoprostol in facilities offering maternity services in Senegal [14] which may be due to lack of awareness of its reproductive health uses and limited supply of the drug.

Making misoprostol and information about its uses widely available in Senegal is important for increasing availability and quality of care for PAC and PPH. Pharmacies can increase awareness of and access to misoprostol and can support its correct use however the findings from this study demonstrate that these potential benefits were not being realised. Since this survey was conducted, in-service training and distribution of training materials for pharmacists and prescribers on misoprostol have been initiated in Senegal. Such interventions have the potential to address the knowledge gaps identified among these key groups. The rationale for increasing access to misoprostol must be highlighted to ensure that pharmacy workers recognise the contribution they can have to reducing maternal mortality in the country.

One of the reasons pharmacy workers gave for not stocking misoprostol was that they were unwilling to stock an abortifacient. This may be due to objection to abortion as reported in other countries [35]. In Senegal, in cases of conscientious objection, pharmacists are required to refer the client to another pharmacist or healthcare provider. Other reasons for this unwillingness to stock misoprostol could be lack of knowledge of the product's registration status and of its legal indications. Wide dissemination of the EML could help de-stigmatise the product and fully inform providers and pharmacist workers of its life-saving properties for women experiencing PPH or in need of PAC [6]. In addition to these actions, further research is required to better understand the knowledge, attitudes and practice of health providers towards misoprostol and to identify barriers that could explain the low levels of prescription of the product.

A strength of this study is the unusually high participation rate despite the lack of financial incentive. It is likely that the endorsement from the Order of Pharmacists, the anonymous nature of the interviews and the explanation by interviewers about the importance of the study played a role in motivating pharmacy workers to take part. The study has a number of limitations. 1) The study was limited to Dakar where transport links are good, and additional research will be needed to assess misoprostol knowledge and provision in other regions of Senegal. 2) It is not clear whether the practice of respondents relate only to individual practice or to a pharmacy-wide policy. 3) Reporting on misoprostol sales and demand for misoprostol medications and information may have been subject to recall bias. Respondents were asked to report on their current practices however misoprostol may be a slowmoving product which could make recall more difficult. 4) Some of the findings may have been subject to reporting bias i.e. respondents may have given answers that they believe are politically correct and/or legally safe. More than one third of pharmacists reported knowing that misoprostol could be used for abortion and may therefore have been hesitant to report stocking or selling it. Underreporting of abortion practices in restrictive countries is known to be high due to fear of prosecution or stigma [36-38]. In this survey, a number of behaviours may be underreported including off-label provision, provision to adolescents, provision for termination of pregnancy (abortion is legal in very few circumstances and pharmacists are not legally allowed to provide them) and provision for PAC (which many perceive to be illegal). It is also possible that provision to married clients and for gastric ulcer are over reported. Further exploration is needed into the possibility that awareness of the link between misoprostol and abortion is inhibiting pharmacy worker's willingness to stock and sell the product. Research methodologies such as mystery clients, which minimize pharmacy workers' self-reporting bias, could be used to explore provision practices further. In-depth interviews could also be used to gain deeper understanding of pharmacy workers' views about the use of misoprostol as an abortifacient and whether stigma affects provision practices. 


\section{Conclusions}

There is an urgent need to boost access to misoprostol in Senegal as a strategy for increasing availability and quality of care for PAC and PPH. Educating pharmacists and pharmacy workers about misoprostol, its indications for use and the correct dosages for each indication, could help efforts to improve access to this important reproductive health commodity in Senegal. Pharmacies are a key component of the supply chain of medications and their role in the scale-up of misoprostol must be clarified promptly.

\section{Abbreviations}

EML: Essential Medicines List; IUFD: Intrauterine Foetal Death; MMR: Maternal Mortality Ratio; NSAID: Non-steroidal anti-inflammatory drugs; PAC: Post Abortion Care; PPH: Postpartum Haemorrhage

\section{Acknowledgements}

The research team thank all individuals and institutions who participated in the design and implementation of this work

\section{Funding}

This study was funded by the Strengthening Evidence for Programming on Unintended Pregnancy (STEP-UP) Research Consortium, which is funded by UKaid from the Department for International Development. The UK Government did not play any role in the design, collection, analysis and interpretation of the data, the writing of the manuscript or the decision to submit the manuscript for publication.

\section{Availability of data and materials}

The dataset is available from Marie Stopes or the Population Council on reasonable request.

\section{Authors' contributions}

ND and TN are Principal investigators of the study. KR is co-investigator. MVM is study advisor. ND, TN, KR and MVM designed the study in collaboration with $\mathrm{EB}$ and $\mathrm{BM}$. EB, RN, BM and ND implemented the study with technical support from KR. KR and KF conducted data analysis and lead the writing of the manuscript. All authors contributed to the manuscript, and approved the final version.

\section{Ethics approval and consent to participate}

Ethical approval was obtained from the Senegal National Ethics Committee for Health Research, the Institutional Review Board of the Population Council and Marie Stopes International Independent Ethics Review Committee. Pharmacy workers gave informed consent to participate in the study prior to the interviews being conducted. Endorsement for the study was obtained from the Order of Pharmacists who contacted all pharmacies in writing encouraging them to participate in the research. Neither pharmacies nor pharmacy workers received financial compensation for their participation.

\section{Consent for publication}

Not applicable.

\section{Competing interests}

KR, KF, EB, RN, MVM and TN worked for Marie Stopes Senegal or Marie Stopes International during study implementation. Marie Stopes Senegal and Marie Stopes International supported the registration of Misoclear in Senegal for PPH and PAC in 2011. ND and BM declare they that have no competing interests.

\section{Publisher's Note}

Springer Nature remains neutral with regard to jurisdictional claims in published maps and institutional affiliations.

\section{Author details}

Health Systems Department, Marie Stopes International, 1 Conway Street, London W1T 6LP, UK. ${ }^{2}$ Marie Stopes International Senegal, Sacre Coeur III, 10082 VDN Dakar, Senegal. ${ }^{3}$ Population Council Senegal, Sacre Coeur Pyrotechnie, Appartement 2ème Etage à Droite, BP: 21027 Dakar, Ponty, Senegal.

Received: 19 October 2015 Accepted: 22 June 2017

Published online: 03 July 2017

\section{References}

1. World Health Organisation. Trends in maternal mortality: 1990 to 2015: estimates by WHO, UNICEF, UNFPA. Geneva: World Bank Group and the United Nations Population Division; 2015

2. Maiga M, Lo A. Repositioning family planning in Senegal: a baseline. 2012

3. World Health Organization. Count down to 2015: Maternal, Newborn and Child Survival, Senegal 2010. http://www.countdown2015mnch.org/ documents/2010/2010-Senegal.pdf (accessed 23 Jul 2015).

4. Ronsmans C, Graham WJ. Maternal mortality: who, when, where, and why Lancet. 2006:368:1189-200. doi:10.1016/S0140-6736(06)69380-X.

5. Say L, Chou D, Gemmill A, Tunçalp Ö, Moller A-B, Daniels J, et al. Global causes of maternal death: a WHO systematic analysis. Lancet Glob Heal. 2014;2:e323-33. doi:10.1016/S2214-109X(14)70227-X.

6. Prata N, Sreenivas A, Vahidnia F, Potts M. Saving maternal lives in resourcepoor settings: facing reality. Health Policy. 2009;89:131-48. doi:10.1016/j. healthpol.2008.05.007.

7. Miller S, Lehman T, Campbell M, Hemmerling A, Anderson SB, Rodriguez $H$, et al. Misoprostol and declining abortion-related morbidity in Santo Domingo, Dominican Republic: a temporal association. BJOG. 2005;112: 1291-6. doi:10.1111/j.1471-0528.2005.00704.x.

8. Diadhiou M, Dieng T, Ortiz C, Mall I, Dione D, Sloan NL. Introduction of misoprostol for prevention of postpartum hemorrhage at the community level in Senegal. Int J Gynaecol Obstet. 2011;115:251-5. doi:10.1016/j.ijgo. 2011.08.002.

9. Derman R, Kodkany B, Goudar S, Geller S, Naik V, Bellad M. Oral misoprostol in preventing postpartum haemorrhage in resource-poor communities: a randomised controlled trial. Lancet. 2006:386

10. World Health Organisation. WHO Model List of Essential Medicines: 16th Edition. Geneva: World Health Organisation; 2009.

11. World Health Organisation. WHO Model List of Essential Medicines: 17th Edition. Geneva: World Health Organisation; 2011.

12. World Health Organisation. WHO Model List of Essential Medicines: 14th Edition. Geneva: World Health Organisation; 2005.

13. Diop A, Daff B, Sow M, Blum J, Diagne M, Sloan NL, et al. Oxytocin via Uniject (a prefilled single-use injection) versus oral misoprostol for prevention of postpartum haemorrhage at the community level: a clusterrandomised controlled trial. Lancet Glob Heal. 2016:4:e37-44. doi:10.1016/ S2214-109X(15)00219-3.

14. Gaye A, Diop A, Shochet T, Winikoff B. Decentralizing postabortion care in Senegal with misoprostol for incomplete abortion. Int J Gynaecol Obstet. 2014;126:223-6. doi:10.1016/j.ijgo.2014.03.028.

15. Vlassoff M, Diallo A, Philbin J, Kost K, Bankole A. Cost-effectiveness of two interventions for the prevention of postpartum hemorrhage in Senegal. Int J Gynecol Obstet. 2016;133:307-11. doi:10.1016/j.jjgo.2015.10.015.

16. Agence Nationale de la Statistique et de la Démographie International (ANSD) SI. Enquête Continue sur la Prestation des Services de Soins de Santé (ECPSS) du Sénégal. Calberton: Agence Nationale de la Statistique et de la Démographie International; 2012.

17. CEFOREP. Revue de la littérature sur les avortements à risque au Sénégal. Dakar: Centre de Formation et de Recherche en Santé de la Reproduction 1998.

18. Sedgh G, Sylla AH, Philbin J, Keogh S, Ndiaye S. Estimates of the incidence of induced abortion and consequences of unsafe abortion in Senegal. Int Perspect Sex Reprod Health. 2015;41:11-9. doi:10.1363/4101115.

19. Thiam F, Suh S, Moreira M. Scaling up postabortion care services: results from Senegal. Occas Pap Manag Sci Heal. 2006; https://www.msh.org/sites/ msh.org/files/scaling-up-postabortion-care-services-results-from-senegal.pdf. Accessed 27 June 2017.

20. Erdman JN. Harm reduction, human rights, and access to information on safer abortion. Int J Gynaecol Obstet. 2012;118:83-6. doi:10.1016/j.jjgo.2012.04.002. 
21. Hyman A, Blanchard K, Coeytaux F, Grossman D, Teixeira A. Misoprostol in women's hands: a harm reduction strategy for unsafe abortion Contraception. 2013;87:128-30. doi:10.1016/j.contraception.2012.10.020.

22. Mayhew S, Nzambi K, Pépin J, Adjei S. Pharmacists' role in managing sexually transmitted infections: policy issues and options for Ghana. Health Policy Plan. 2001;16:152-60.

23. Chalker J, Chuc NT, Falkenberg T, Do NT, Tomson G. STD management by private pharmacies in Hanoi: practice and knowledge of drug sellers. Sex Transm Infect. 2000;76:299-302. doi:10.1136/sti.76.4.299.

24. Goel P, Ross-Degnan D, Berman P, Soumerai S. Retail pharmacies in developing countries: a behavior and intervention framework. Soc Sci Med. 1996;42:1155-61.

25. Ahmed SM, Hossain MA. Knowledge and practice of unqualified and semiqualified allopathic providers in rural Bangladesh: implications for the HRH problem. Health Policy. 2007:84:332-43. doi:10.1016/j.healthpol.2007.05.011.

26. Beitz J. Increasing access to reproductive health services through pharmacists. Outlook. 2004;21

27. Sneeringer RK, Billings DL, Ganatra B, Baird TL. Roles of pharmacists in expanding access to safe and effective medical abortion in developing countries: a review of the literature. J Public Health Policy. 2012;33:218-29. doi:10.1057/jphp.2012.11

28. Akiode A, Fetters T, Okoh M, Dah T, Akwuba B, Oji E, et al. The availability of misoprostol in pharmacies and patent medicine stores in two Nigerian cities. Ebonyi Med J. 2010;9:96-100. doi:10.4314/ebomed.v9i2.71688.

29. Cartwright A. Pharmacy employee knowledge and attitudes related to misoprostol and abortion in Tanzania. 141st APHA Annu. Meet. (November 2 - Novemb. 6, 2013), APHA; 2013.

30. Adinma E, Adinma J. Knowledge and inventory Management of Misoprostol for reproductive health services amongst community pharmacists in Anambra and Delta states of Nigeria. Afrimedic J. 2013;2:13-8.

31. World Health Organisation. Global strategy on human resources for health. Geneva: Workforce 2030 (Draft); 2015.

32. World Health Organisation. Task shifting: rational redistribution of tasks among health workforce teams. Geneva: Global Recommendations and Guidelines; 2008

33. World Health Organisation. Annex 8 Joint FIP/WHO guidelines on good pharmacy practice: standards for quality of pharmacy services. 2011.

34. Shochet T, Diop A, Gaye A, Nayama M, Sall AB, Bukola F, et al. Sublingual misoprostol versus standard surgical care for treatment of incomplete abortion in five sub-Saharan African countries n.d. doi:10.1186/1471-2393-12-127.

35. Cohen J, Ortiz O, Llaguno SE, Goodyear L, Billings D, Martinez I. Reaching women with instructions on misoprostol use in a Latin American country. Reprod Health Matters. 2005;13(26):84-92.

36. Singh S, Remez L, Tartaglione A. Methodologies for estimating abortion incidence and abortion-related Morbidity : a review. New York and Paris: Guttmacher Institute and Paris International Union for the Scientific Study of Population; 2010.

37. Reiss $\mathrm{K}$, Aung $\mathrm{O}$, Aung MM, Ngo TD. Availability and provision of Abortifacients among pharmacies in a restricted southeast Asian City. Pharm Care Heal Syst. 2014:S1-5.

38. Sedgh G, Singh S, Shah IH, Ahman E, Henshaw SK, Bankole A. Induced abortion: incidence and trends worldwide from 1995 to 2008. Lancet. 2012; 379:625-32. doi:10.1016/50140-6736(11)61786-8.

\section{Submit your next manuscript to BioMed Central and we will help you at every step:}

- We accept pre-submission inquiries

- Our selector tool helps you to find the most relevant journal

- We provide round the clock customer support

- Convenient online submission

- Thorough peer review

- Inclusion in PubMed and all major indexing services

- Maximum visibility for your research

Submit your manuscript at www.biomedcentral.com/submit

) Biomed Central 